Article

\title{
Synthesis and Application of Cerium-Incorporated SBA-16 Supported Ni-Based Oxygen Carrier in Cyclic Chemical Looping Steam Methane Reforming
}

\author{
Maryam Meshksar, Mohammad Reza Rahimpour *, Sanaz Daneshmand-Jahromi and Ali Hafizi \\ Department of Chemical Engineering, Shiraz University, Shiraz 71345, Iran; \\ Meshksar.maryam@gmail.com (M.M.); Sanaz.daneshmand@yahoo.com (S.D.-J.); hafizi@shirazu.ac.ir (A.H.) \\ * Correspondence: rahimpor@shirazu.ac.ir; Tel.: +98-713-613-3673
}

Received: 31 October 2017; Accepted: 25 December 2017; Published: 10 January 2018

\begin{abstract}
Hydrogen, as a clean energy carrier, could be produced aided by cyclic oxidation-reduction of oxygen carriers (OCs) in contact with carbonaceous fuel in chemical looping steam methane reforming (CL-SMR) process. In this study, the cerium was incorporated into the SBA-16 support structure to synthesize the Ni/Ce-SBA-16 OC. The supports were synthesized using hydrothermal method followed by impregnation of $\mathrm{Ni}$ and characterized via low and wide angle $\mathrm{X}$-ray diffraction (XRD), Brunauer-Emmett-Teller (BET), scanning electron microscopy (SEM), coupled with energy dispersive X-ray (EDX) spectroscopy, and transmission electron micrograph (TEM) techniques. In addition, the effect of various $\mathrm{Si} / \mathrm{Ce}$ molar ratios (20-60) in the support structure, Ni loading $(10-30 \mathrm{wt} \%)$, reaction temperature $\left(500-750{ }^{\circ} \mathrm{C}\right)$, and life time of optimal oxygen carrier over 16 cycles were investigated. The results of wide angle XRD and SEM revealed that the incorporation of $\mathrm{CeO}_{2}$ in the channels of SBA- 16 caused the formation of nickel metallic particles with smaller size and prevents the coke formation. The results showed that $\mathrm{OC}$ with $15 \mathrm{wt} \% \mathrm{Ni}$ and $\mathrm{Si} / \mathrm{Ce}$ molar ratio of 40 (15Ni/Ce-SBA-16(40)) has the best performance when compared with other OCs in terms of catalytic activity and structural properties. The methane conversion of about $99.7 \%$ was achieved at $700{ }^{\circ} \mathrm{C}$ using $15 \mathrm{Ni} / \mathrm{Ce}-\mathrm{SBA}-16(40) \mathrm{OC}$. We anticipate that the strategy can be extended to investigate a variety of novel modified mesoporous silica as the supporting material for the Ni based OCs.
\end{abstract}

Keywords: chemical looping reforming; cerium incorporated SBA-16; mesoporous silica; oxygen carrier; hydrogen production

\section{Introduction}

Hydrogen is an energy carrier that is used in various chemical and petrochemical industries, such as methanol and ammonia production, petroleum refineries and fuel cells [1-4]. Since combustion of fossil fuels releases different greenhouse gases, such as $\mathrm{CO}_{2}, \mathrm{NO}_{\mathrm{x}}, \mathrm{SO}_{\mathrm{x}}$, and $\mathrm{CH}_{4}$ that causes global warming effect. Hydrogen can replace these fuels [5-8].

Reforming of hydrocarbons is a well-known process for the production of hydrogen and carbon monoxide [9]. One of the reforming reactions that is conventionally used for this purpose is the partial oxidation of hydrocarbon. In this process, the oxygen source could be supplied from either air or pure oxygen. In the first oxygen source, the product is diluted with nitrogen, whereas in the second one, an oxygen plant is required $[10,11]$. In order to reduce the cost of reforming, chemical looping reforming (CLR) process was suggested by Mattisson and Lyngfelt [12]. One of the most important hydrocarbon sources that can be used in reforming process is methane. It has received much attention due to its low cost and high availability [13]. As indicated in Figure 1, in chemical looping steam methane reforming (CL-SMR) process, methane is converted to synthesis gas in contact with oxygen carriers in the fuel reactor while the reduced oxygen carriers is reoxidized in the air reactor [14,15]. 


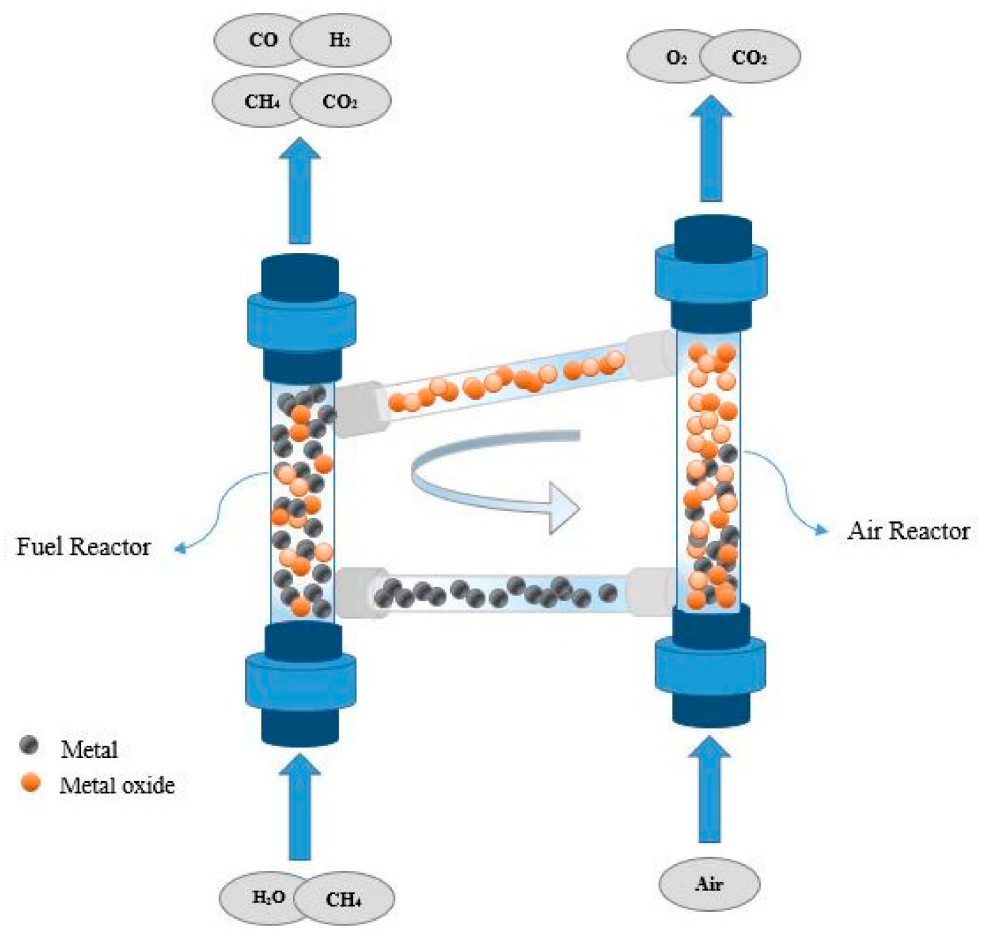

Figure 1. Conceptual scheme of chemical looping steam methane reforming (CL-SMR).

The principle reactions that occur in the fuel reactor of CL-SMR process are as follows [16-18]:

$$
\begin{gathered}
s \mathrm{CH}_{4}+\mathrm{Me}_{x} \mathrm{O}_{y} \rightarrow \mathrm{Me}_{x} \mathrm{O}_{y-s}+s \mathrm{CO}+2 \mathrm{H}_{2} \\
\mathrm{CO}+\mathrm{H}_{2} \mathrm{O} \leftrightarrow \mathrm{H}_{2}+\mathrm{CO}_{2}
\end{gathered}
$$

In the air reactor, the oxygen carriers (OC) is converted to its initial oxidized form through the following reaction:

$$
2 \mathrm{Me}_{x} \mathrm{O}_{y-s}+s \mathrm{O}_{2} \rightarrow \mathrm{Me}_{x} \mathrm{O}_{y}
$$

The reason that Equation (1) in reduced catalyst is not followed by partial oxidation of $\mathrm{CO}$ in oxidized catalyst is that $\mathrm{CO} \rightarrow \mathrm{CO}_{2}$ reaction is an exothermic reaction with $\Delta \mathrm{H}=-283 \mathrm{~kJ} / \mathrm{mol}$ that occurs in low temperatures. As the reaction temperature of reforming process is high, the reverse reaction of partial oxidation of $\mathrm{CO}$ is occurred.

The choice of oxygen carrier plays an important role in CLR process. The OC must have enough oxygen transport capacity, high selectivity towards synthesis gas, high stable performance for successive cycles, and low tendency toward coke formation $[19,20]$. The OC is comprised of a porous support and redox active sites.

Some metal oxides including $\mathrm{NiO}, \mathrm{CuO}, \mathrm{Fe}_{2} \mathrm{O}_{3}, \mathrm{CoO}$, and $\mathrm{MnO}_{2}$ are considered as effective oxygen carriers to promote CLR procedure. It was reported that Ni-based OCs revealed high oxygen transfer rate and capacity. In addition, the cyclic chemical looping results showed the high selectivity toward $\mathrm{H}_{2}$ and $\mathrm{CO}$ using $\mathrm{Ni} \mathrm{OC}$ [21]. Diego et al. [22] tested $\mathrm{NiO}-\gamma \mathrm{Al}_{2} \mathrm{O}_{3}$ oxygen carrier in the CLR using methane as fuel and determined the effect of different operating variables, such as the temperature of fuel reactor in the range of $800-900{ }^{\circ} \mathrm{C}, \mathrm{H}_{2} \mathrm{O} / \mathrm{CH}_{4}$ molar ratio (0-0.5), and solid circulation rate. Their results showed that $\mathrm{OC}$ conversion was increased at higher temperatures and with increasing $\mathrm{H}_{2} \mathrm{O} / \mathrm{CH}_{4}$ molar ratio, $\mathrm{H}_{2}$, and $\mathrm{CO}_{2}$ conversions were increased, whereas $\mathrm{CO}$ conversion was decreased. Liu and his coworkers [23] prepared Ni grafted SBA-15 and MCM-41 catalysts for $\mathrm{CO}_{2}$ reforming of methane. The obtained results showed that $5 \mathrm{wt} \% \mathrm{Ni} / \mathrm{SBA}-15$ catalyst has the highest catalytic activity and long-time stability. 
Nevertheless, the dispersed $\mathrm{Ni}$ active sites are quickly deactivated because of coke formation and/or sintering of the support and metallic phases in CL-SMR process [24].

Mesoporous materials could be applied as the support of OC to improve Ni active sites dispersion and prevent the aggregation of Ni nanoparticles. They include a range of large surface area, with diameters in the range of 2-50 $\mathrm{nm}$. One kind of porous based materials are SBA-type silica groups. The SBA-16 mesoporous silica is known as one of the novel structure of this family. Thick pore walls, high surface area, prominent thermal and hydrothermal stability, three-dimensional (3D) and cubic structure make SBA-16 be an outstanding catalyst or support [25]. However, as pure SBA-16 suffers from lack of sufficient acidity and coke deposition, the modification seems to be needed.

A suggested solution is the modification of support structure with an appropriate promoter such as $\mathrm{CeO}_{2}, \mathrm{La}_{2} \mathrm{O}_{3}, \mathrm{CaO}, \mathrm{Al}_{2} \mathrm{O}_{3}$, and $\mathrm{MgO}$ [10,26-30]. Lindo et al. [26] assessed Ni catalysts supported on Al-SBA-15 mesoporous materials for ethanol steam reforming. They found that the incorporation of $\mathrm{Al}^{3+}$ cations into the frame work of SBA-15 leads to strong interaction between $\mathrm{NiO}$ active sites and Al-SBA-15 carrier. Qian et al. [27] have proved that the presence of La in Ni/SBA-15 in methane dry reforming significantly improved catalytic activity and stability. The $\mathrm{CO}_{2}$ adsorption capacity was increased by addition of La into the framework of SBA-15.

The redox properties of $\mathrm{CeO}_{2}\left(\mathrm{Ce}^{4+} \leftrightarrow \mathrm{Ce}^{3+}\right)$ improve the mobility of surface oxygen that lowers carbon deposition on active sites. Also, the metal-support interaction and the dispersion of metal particles are increased in the presence of $\mathrm{CeO}_{2}$ [31]. Wang et al. [28] tested Ce-SBA-15 supported nickel OC synthesized by direct hydrothermal method in methane reforming with $\mathrm{CO}_{2}$. The results showed that the cerium incorporated in the framework of SBA-15 leads to formation of nickel particles with smaller size, which prevents the carbon deposition. $\mathrm{Li}$ and her coworkers [32] examined $\mathrm{CeO}_{2}$-promoted Ni/SBA-15 catalysts in ethanol steam reforming. The results revealed that the incorporated $\mathrm{CeO}_{2}$ particles promote the homogeneous distribution of $\mathrm{Ni}$ and $\mathrm{Ce}$ in order to achieve large $\mathrm{Ni} / \mathrm{CeO}_{2}$ interface.

To the best of our knowledge, this is the first paper on the incorporation of cerium into the framework of SBA-16 and its application as the supporting material of Ni-based OC in CL-SMR process. The aim of this paper is to synthesize Ce-SBA-16 support by the hydrothermal method and to impregnate nickel on this modified support to have Ni-based OC. In addition, various characterizations were performed to investigate the surface and textural properties of the supports, used and fresh OC. Some parameters, such as Ni loading percentage, the effect of Si to Ce molar ratio in the support, reaction temperature, and life time of optimum OC over 16 cycles were studied.

\section{Results and Discussion}

\subsection{Sample Characterization}

Low angle XRD pattern of Ce-SBA-16(40) (Figure 2) shows a main peak at $2 \theta$ value of about $0.9^{\circ}$ and a less peak at $2 \theta$ equal to $2.2^{\circ}$, respectively, corresponding to 110 and $211 \mathrm{Bragg}^{\prime}$ s reflections. These two peaks could be indexed to a mesoporous 3D cubic structure of SBA- 16 with space group of $1 \mathrm{~m} 3 \mathrm{~m}$ [33]. Previous authors synthesized various metal incorporated SBA-16 materials and characterized them with low angle XRD. They showed that the SBA-16 structure was preserved after incorporation of different loadings of metal into the structure of SBA-16 [34,35].

Figure 3 indicates a comparison between wide angle XRD patterns of unreacted 15Ni/Ce-SBA-16(40) and $15 \mathrm{Ni} / \mathrm{Ce}-\mathrm{SBA}-16(\infty)$ OCs. According to Figure $3 \mathrm{~b}$, Ce is observed in the form of $\mathrm{CeO}_{2}$ and $\mathrm{CeNi}_{2}$ in modified supported OC. Also, in this figure, $\mathrm{SiO}_{2}$ peaks are slightly shifted to right because of larger ionic radii of $\mathrm{Ce}^{4+}$ when compared with $\mathrm{Si}^{4+}$, which is proved the presence of Ce particles in the framework of SBA-16 [36]. As indicated in this figure, by the addition of cerium into the framework of SBA-16, $\mathrm{NiO}$ peaks $\left(2 \theta=37^{\circ}, 43^{\circ}, 63^{\circ}, 76^{\circ}\right.$, and $\left.79^{\circ}\right)$ became wider that indicates the presence of $\mathrm{Ce}$ caused fine nickel oxide particles on the surface of OC. This can be proved by debye sherrer equation. From this equation, the average $\mathrm{NiO}$ particle size was $8.8 \mathrm{~nm}$ for $15 \mathrm{Ni} / \mathrm{Ce}-\mathrm{SBA}-16(40)$ and $14.1 \mathrm{~nm}$ for 
$15 \mathrm{Ni} / \mathrm{Ce}-\mathrm{SBA}-16(\infty)$ oxygen carriers. According to $01-083-2071$ reference pattern code, $\mathrm{Ni}_{2} \mathrm{SiO}_{4}$ is observed at peaks of $2 \theta=35^{\circ}, 38^{\circ}, 45^{\circ}$, and $51^{\circ}$.

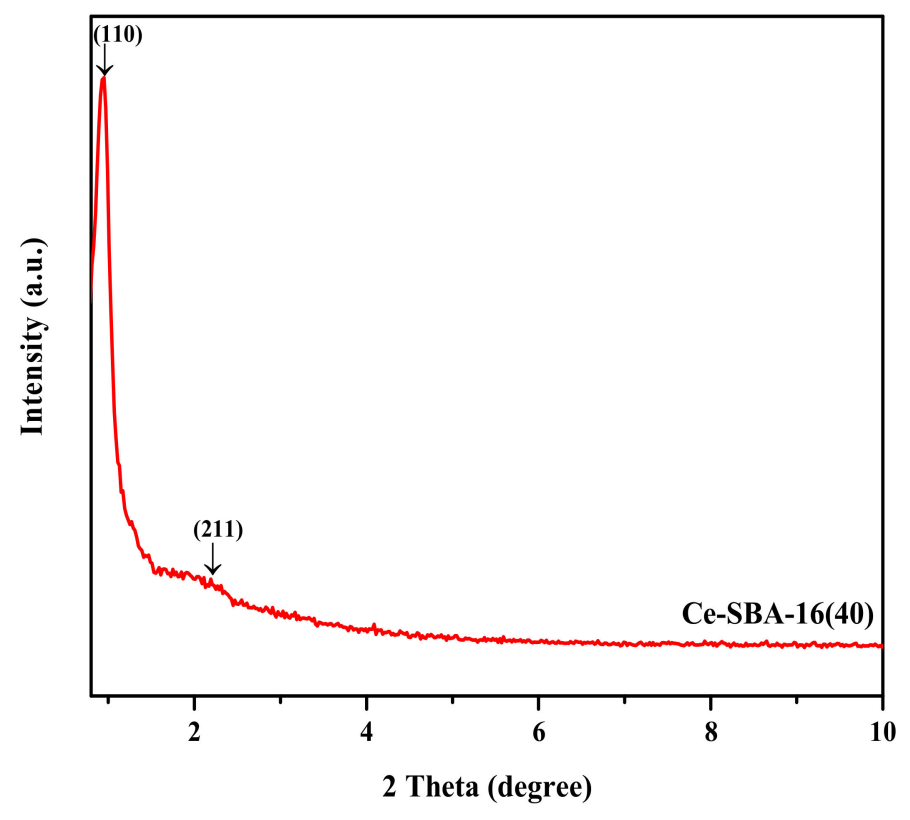

Figure 2. Low angle XRD pattern of Ce-SBA-16(40) support.

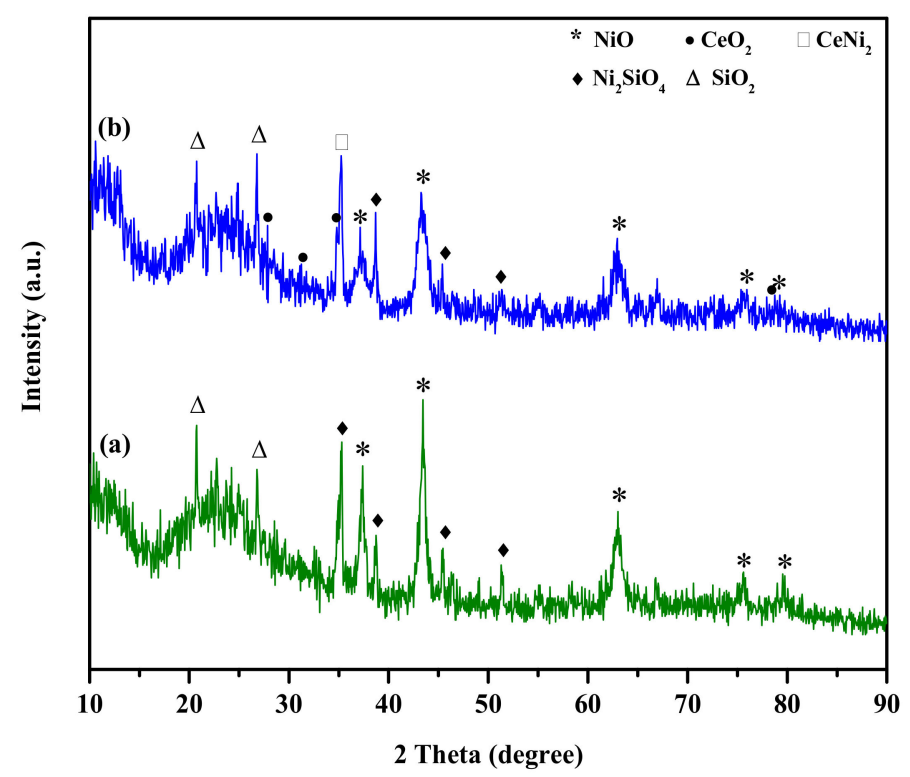

Figure 3. Wide angle XRD patterns of (a) Fresh 15Ni/Ce-SBA-16( $\infty$ ) and (b) Fresh 15Ni/Ce-SBA-16(40) oxygen carriers (OCs).

In order to investigate the porous structure of catalysts, the $\mathrm{N}_{2}$ adsorption/desorption isotherms of Ce-SBA-16( $\infty)$, Ce-SBA-16(20), Ce-SBA-16(40), Ce-SBA-16(60) supports, and 15Ni/Ce-SBA-16(40) OC are shown in Figure 4a. As can be seen in this figure, all of the prepared samples exhibit type-IV isotherms with a $\mathrm{H}_{2}$ hysteresis loop characteristic of mesoporous oxygen carrier with cubic cage-like structure. For all the samples, the first hysteresis loop starts at $\mathrm{P} / \mathrm{P}_{0}=0.4$, demonstrating the presence of messoporous framework and the second hysteresis loop that starts at $\mathrm{P} / \mathrm{P}_{0}=0.7$ showing the mesoporosity of inter-particles. When compared with pure SBA-16, the inflection point of modified supports hysteresis shifts to higher values of the $\mathrm{P} / \mathrm{P}_{0}$. This shift reveals that Ce-metal oxide particles could be incorporated 
into the inner structure of SBA-16, which is in accordance with XRD results [37]. The impregnated sample (15Ni/Ce-SBA-16(40)) represents a very narrow hysteresis loop area with a low quality of type-IV $\mathrm{N}_{2}$ adsorption/desorption isotherm, which may be caused by the coexistence of disordered mesoporous structure [38]. In addition, it seems to be related to the pore blockage due to $\mathrm{Ni}$ deposition on the pore gate. The pore size distribution of Ce-SBA-16(y) (20, 40, 60 and $\infty$ ) supports and fresh 15Ni/Ce-SBA-16(40), as obtained from Barret-Joyner-Halenda (BJH) method, are illustrated in Figure 4b. The Ce-SBA-16(20, 40) supports show a narrow and sharp peak, indicating that these materials possess uniform mesopore structure. Whereas, Ce-SBA-16(60) has a wide and less sharp peak with an average pore diameter centered at $3.49 \mathrm{~nm}$. A much wider range of size distribution is obtained by impregnating nickel on the Ce-SBA-16(40) support revealing the existence of the pore blocking phenomena.
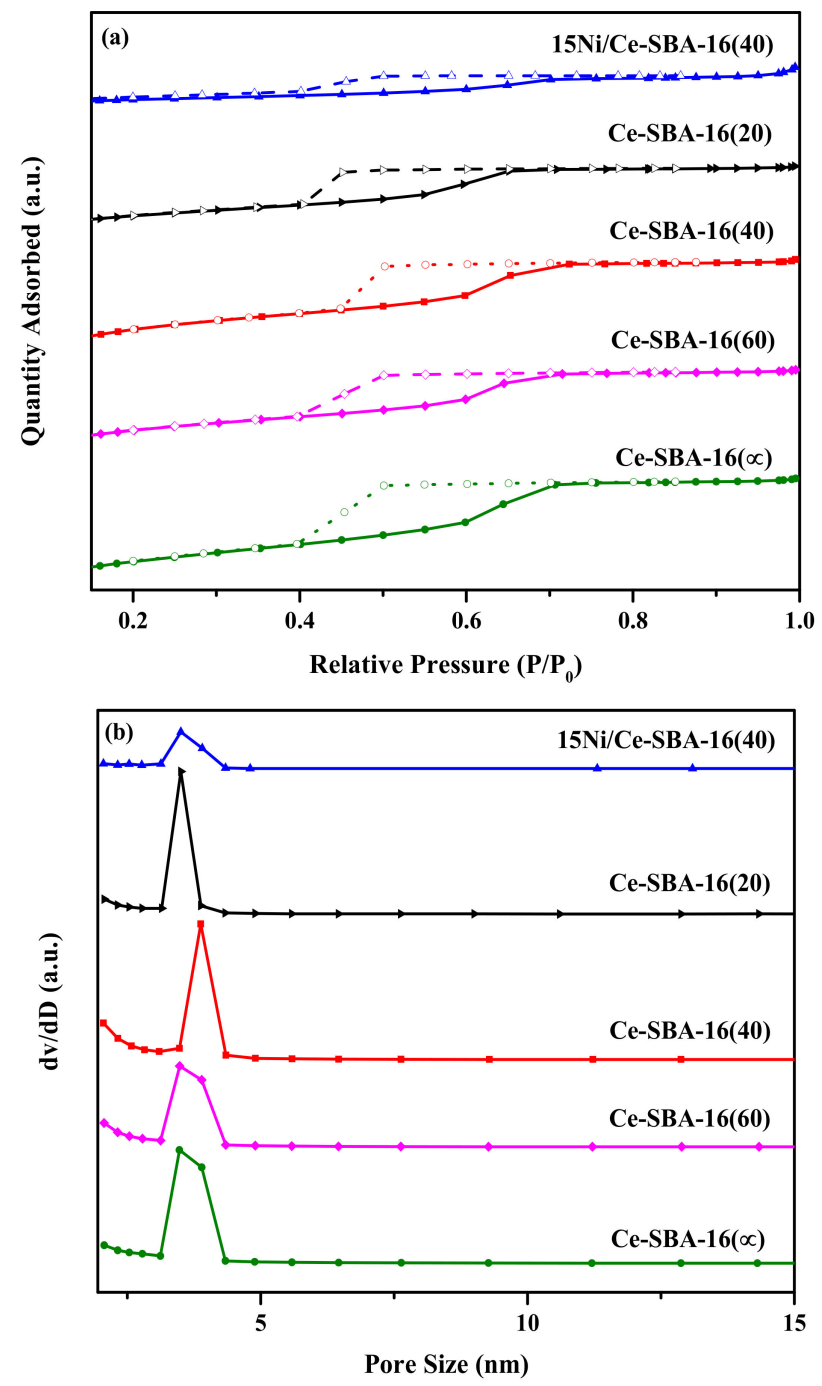

Figure 4. (a) $\mathrm{N}_{2}$ adsorption/desorption isotherms and (b) Pore size distribution of Ce-SBA-16( $\infty$ ), Ce-SBA-16(20), Ce-SBA-16(40), Ce-SBA-16(60), and Fresh 15Ni/Ce-SBA-16(40) OCs.

The structure characteristics of various mesoporous supports are presented in Table 1. It can be observed that BET surface area of ordered Ce containing samples (Ce-SBA-16(20, 40, 60)) are larger than Ce-SBA-16( $\infty)$. This is because the radius of $\mathrm{Ce}^{4+}$ cation is larger than $\mathrm{Si}^{4+}$ so the length of $\mathrm{Ce}-\mathrm{O}$ bond formed is longer than that of $\mathrm{Si}-\mathrm{O}$ bond length. Substitution of Ce species for $\mathrm{Si}^{4+}$ leads to a significant expansion in the mesoporous structure. This confirms that Ce species were incorporated into the framework of silica, which is in good agreement with those that were obtained by wide angle XRD [36]. 
The surface area of Ce-SBA-16(y) supports tended to be increased with $\mathrm{Si} / \mathrm{Ce}$ ratio from $\mathrm{y}=60-40$. Further increase in Ce content ( $\mathrm{Si} / \mathrm{Ce}$ ratio from 40 to 20) revealed negative effect on the surface area. The pore volume and average pore size follow the similar trend with the surface area. Among the supports, Ce-SBA-16(20) displays the lowest specific surface area, pore diameter, and pore volume, because the ordered mesoporous structure of Ce-SBA-16(20) was partially destroyed. It may be the result of partial blockage of SBA-16 pores which was occurred due to presence of the cerium ions on the silica wall or even by partial collapse of the mesoporous silica structure along with the incorporation of excessive cerium. It can be observed that among Ce modified OC supports, Ce-SBA-16(40) exhibits the highest surface area, pore diameter, and pore volume. After the impregnation of $\mathrm{Ni}$ on Ce-SBA-16(40) support, the specific surface area is decreased significantly. It seems to be due to the size of $\mathrm{NiO}$ particles, which are bigger than the pore size of the support. Thus, partial blockage of pores could be occurred [39]. This is in line with the results of pore size distribution curve indicated in Figure $4 \mathrm{~b}$.

Table 1. Structure characteristics of Ce-SBA-16(20, 40, 60, $\infty)$ and fresh 15Ni/Ce-SBA-16(40) OC.

\begin{tabular}{|c|c|c|c|}
\hline Sample & BET Surface Area $\left(\mathrm{m}^{2} / \mathrm{g}\right)$ & Pore Diameter $(\mathrm{nm})^{b}$ & Pore Volume $\left(\mathrm{cm}^{3} / \mathrm{g}\right)$ \\
\hline Ce-SBA- $16\left(\infty^{a}\right)$ & 538.19 & 3.4 & 0.27 \\
\hline Ce-SBA-16(60) & 700.55 & 3.41 & 0.28 \\
\hline Ce-SBA-16(40) & 801.02 & 3.42 & 0.33 \\
\hline Ce-SBA-16(20) & 540.47 & 3.38 & 0.23 \\
\hline 15Ni/Ce-SBA-16(40) & 207.15 & 4.57 & 0.25 \\
\hline
\end{tabular}

${ }^{a}$ molar ratio of $\mathrm{Si} / \mathrm{Ce}$ in the synthesis gel. ${ }^{\mathrm{b}} \mathrm{BJH}$ desorption average pore diameter. ${ }^{\mathrm{c}} \mathrm{BJH}$ desorption pore volume.

For further observation of structural properties, TEM images of Ce-SBA-16(40) and 15Ni/ Ce-SBA-16(40) are exhibited in Figure 5. The Ce-SBA-16(40) support represents uniform mesoporous cubic structure with $1 \mathrm{~m} 3 \mathrm{~m}$ space group, which is in agreement with low angle XRD results. As indicated in Figure 5b, with the impregnation of nickel on Ce-SBA-16(40) support, NiO particles caused the loss of ordered mesopores.

The shape of nickel particles and surface morphology of the OCs could be seen in SEM images before and after CL-SMR process (Figure 6). This figure indicates that after reaction, cubic $\mathrm{NiO}$ particles transform into spherical particles. This is because these particles reused several times. With increasing Ce content up to 40 , smaller $\mathrm{NiO}$ particles can be observed in both used and fresh OCs. This is the result of higher surface area of Ce-SBA-16(40) support when compared with Ce-SBA-16(20, 60) supports that leads to higher and better dispersion of $\mathrm{NiO}$ particles on the surface of supports, which is in accordance with the results of wide angle XRD. The average particle size of $15 \mathrm{Ni} / \mathrm{Ce}-\mathrm{SBA}-16(40)$ is about $75 \mathrm{~nm}$, while it is 120 and $100 \mathrm{~nm}$ for 15Ni/Ce-SBA-16(20) and 15Ni/Ce-SBA-16(60) OCs, respectively. Figure 6a shows that after incorporation of Ce into the framework of SBA-16, the three-dimensional structure of SBA-16 is preserved, which is consistent with the results of low angle XRD.

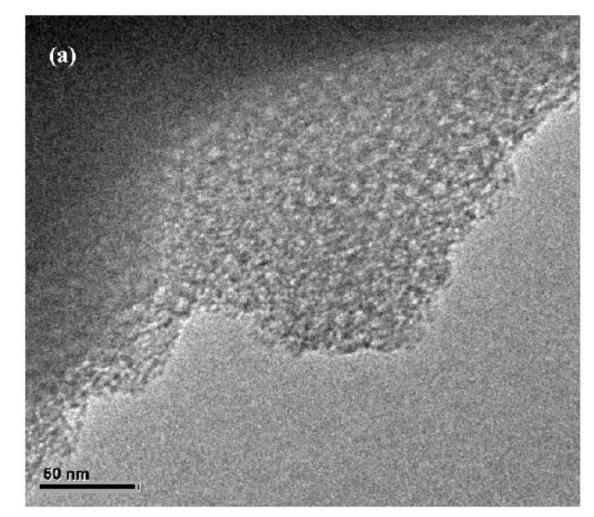

Figure 5. Cont. 


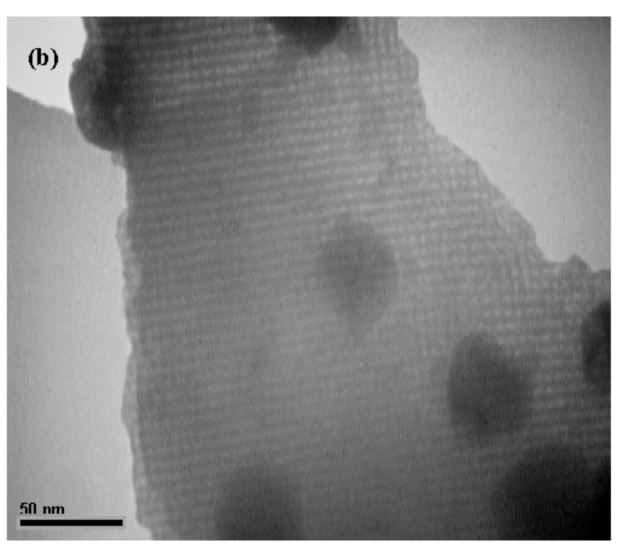

Figure 5. TEM images of (a) Ce-SBA-16(40) and (b) Fresh 15Ni/Ce-SBA-16(40) OC.

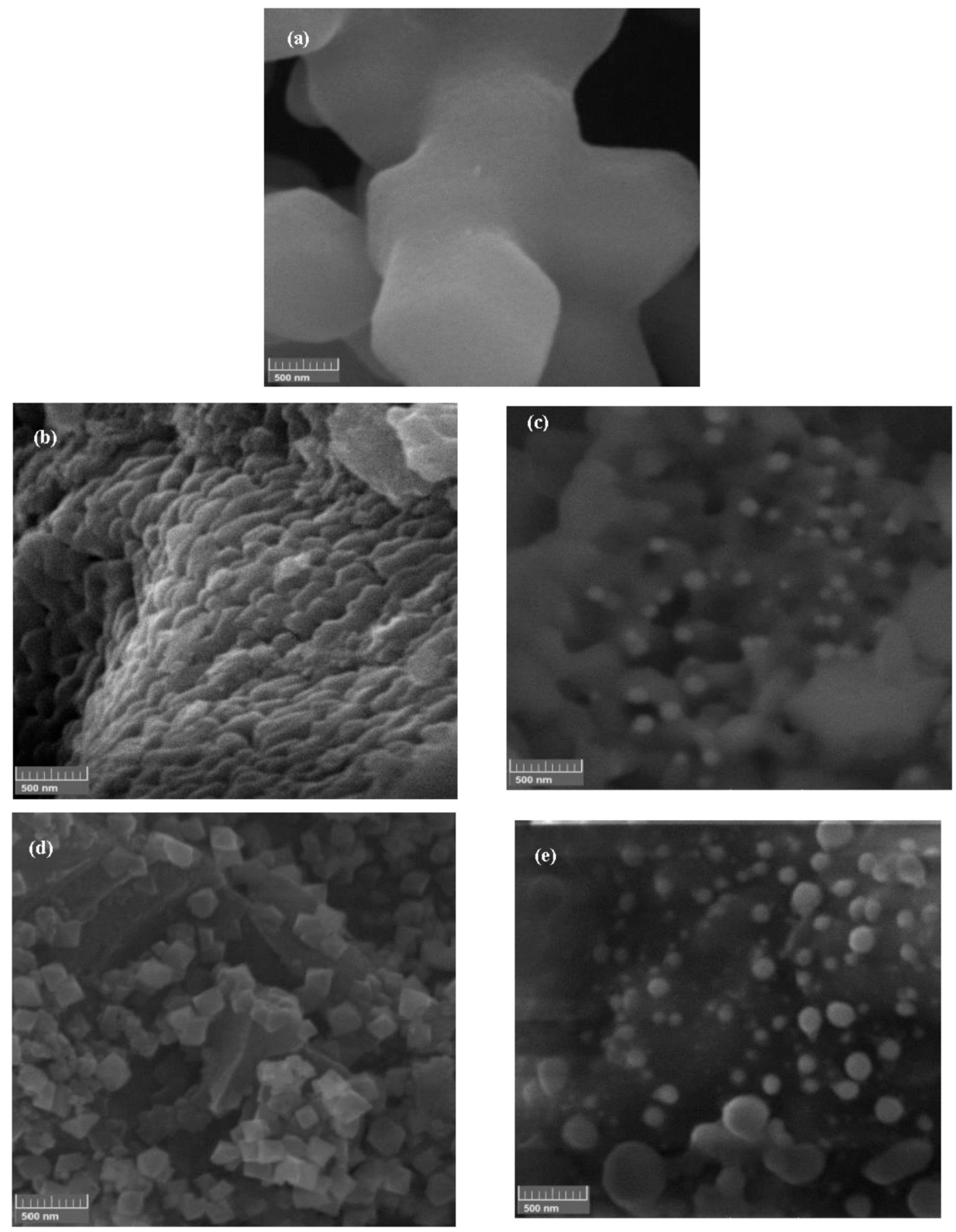

Figure 6. Cont. 

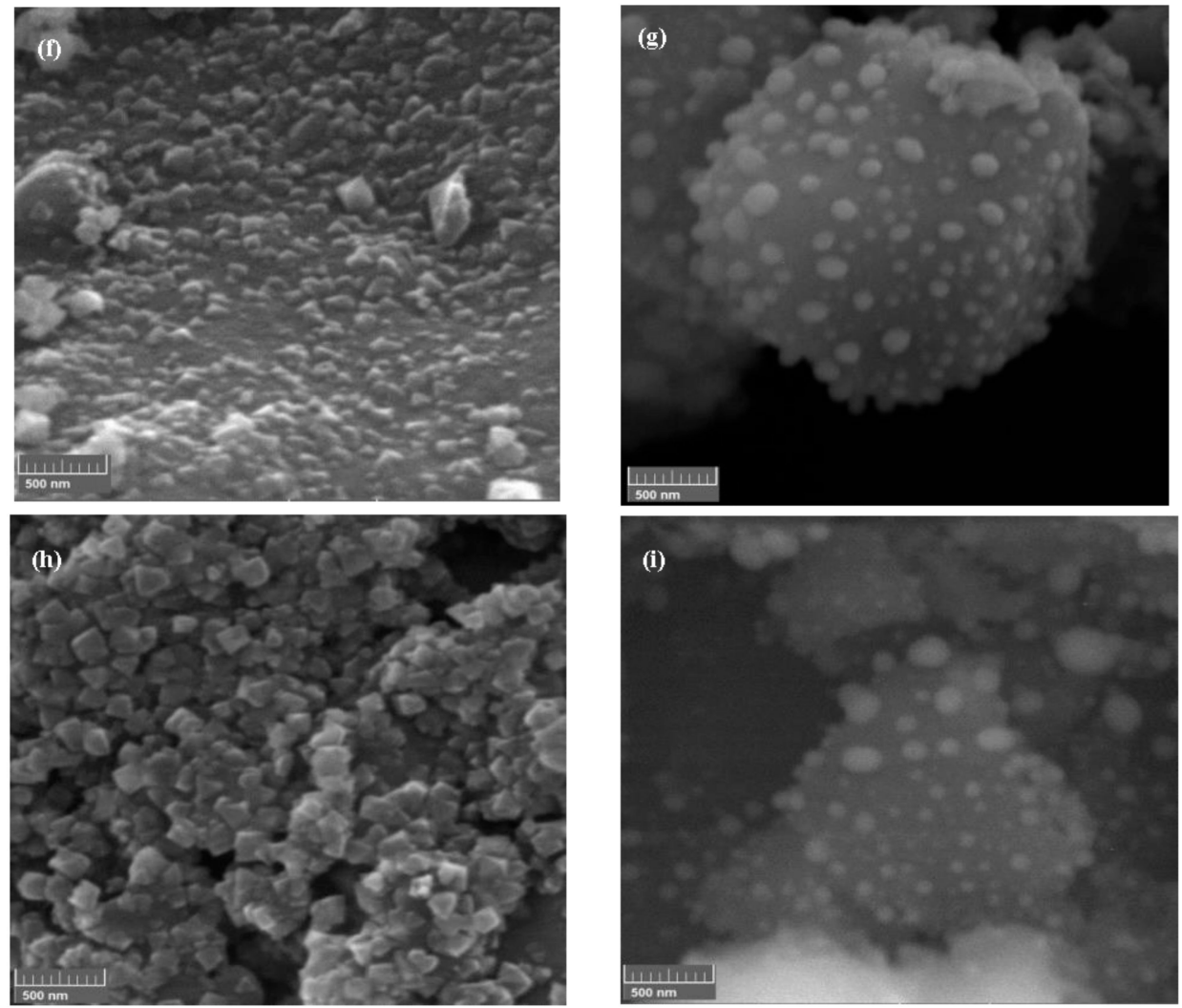

Figure 6. SEM images of (a) Ce-SBA-16(40) (b) Fresh 15Ni/Ce-SBA-16( $\infty$ ); (c) Used 15Ni/Ce-SBA-16( $\infty$ ); (d) Fresh 15Ni/Ce-SBA-16(60); (e) Used 15Ni/Ce-SBA-16(60); (f) Fresh 15Ni/Ce-SBA-16(40); (g) Used 15Ni/Ce-SBA-16(40); (h) Fresh 15Ni/Ce-SBA-16(20); and, (i) Used 15Ni/Ce-SBA-16(20) OCs.

To sum, the slight shift of the $\mathrm{SiO}_{2}$ peaks in XRD figure and increase in specific surface area of modified oxygen carriers are the result of incorporation of Ce particles in the SBA-16 framework.

\subsection{Effect od Si to Ce Molar Ratios on the Activity}

The effect of cerium addition to the SBA-16 structure on the oxygen carrier performance is shown in Figure 7a,b. As can be seen in Figure 7a, the methane conversion was increased by raising temperature from 500 to $750{ }^{\circ} \mathrm{C}$ due to endothermic nature of steam methane reforming [40-42]. In addition, the oxygen transform rate of Ni-based oxygen carrier is improved at elevated temperatures. By raising Si/Ce molar ratio in the support structure from 20 to 60, it can be clearly observed that 20Ni/Ce-SBA-16(40) showed the highest activity, especially at lower reaction temperatures. For instance, by increasing temperature up to $650{ }^{\circ} \mathrm{C}$, average methane conversion is increased from about 58.8 to 91.4 for 20Ni/Ce-SBA-16(40), while it is about 87.5 and 87.1 at $650{ }^{\circ} \mathrm{C}$ for $20 \mathrm{Ni} / \mathrm{Ce}-\mathrm{SBA}-16(60)$ and 20Ni/Ce-SBA-16(20), respectively. The average $\mathrm{H}_{2}$ production yield exhibited that the sample with $\mathrm{Si} / \mathrm{Ce}=40$ has better proficiency at all of the temperatures. In addition, hydrogen production yield is increased from 58.0 to $85.0 \%$, with increasing the temperature from 500 to $750{ }^{\circ} \mathrm{C}$ for 20Ni/Ce-SBA-16(40) OC (Figure 7b). 

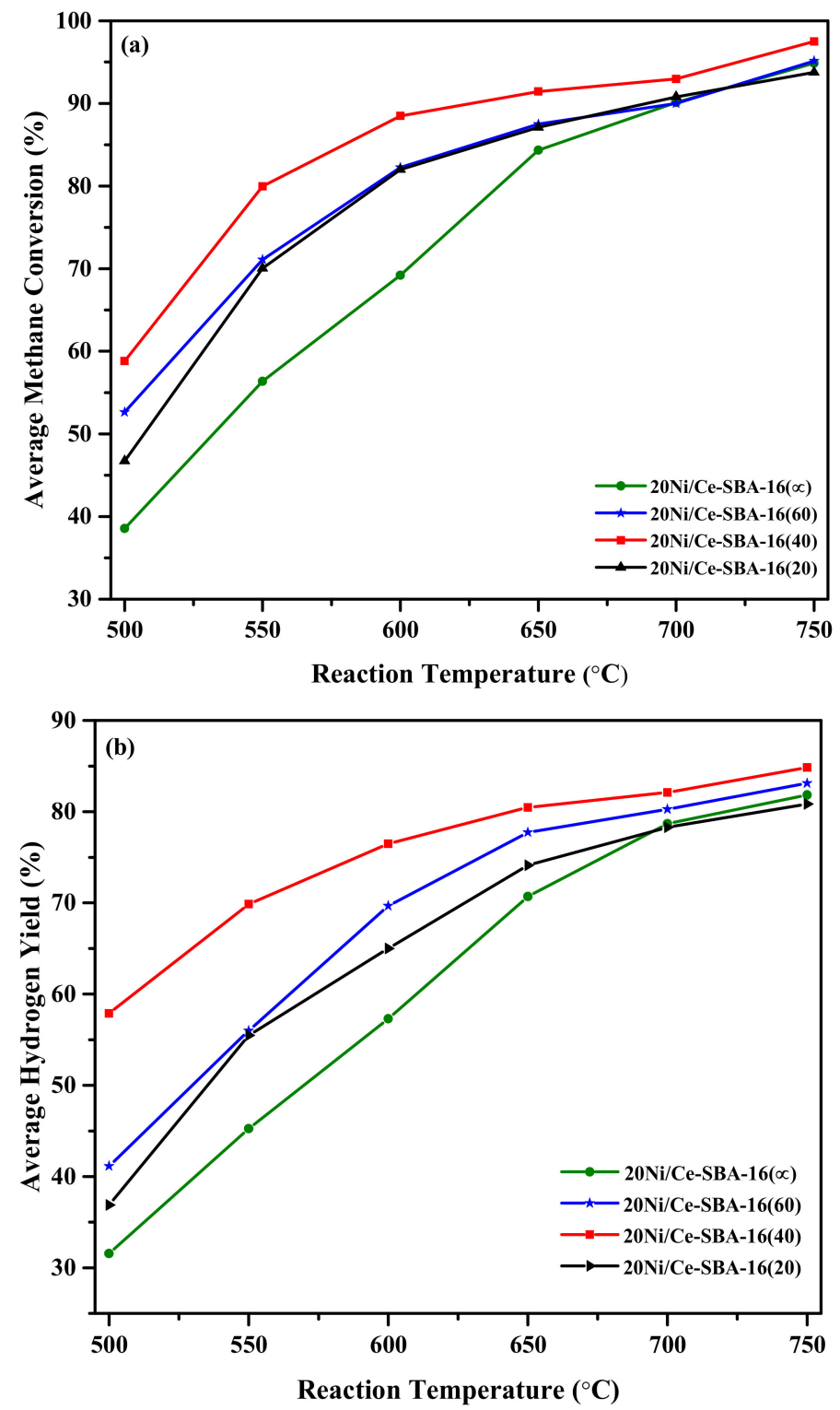

Figure 7. The effect of various $\mathrm{Si}$ to $\mathrm{Ce}$ molar ratio in the support on catalytic activity of 20Ni/Ce-SBA-16(y) OC at different reaction temperatures: (a) Average methane conversion and (b) Average hydrogen yield.

\subsection{Effect of Ni Loading Percentage on the Performance of $x \mathrm{Ni} / \mathrm{Ce}-\mathrm{SBA}-16(40)$}

Figure $8 \mathrm{a}, \mathrm{b}$ demonstrates the effect of $\mathrm{Ni}$ loading on the catalytic activity of $\mathrm{xNi} / \mathrm{Ce}-\mathrm{SBA}-16(40)$ $(x=10,15,20,25,30 \mathrm{wt} \%)$ oxygen carrier in different reaction temperatures. In both figures with increasing temperature, the catalytic performance is increased, and 15Ni/Ce-SBA-16(40) OC has the highest activity, especially in lower temperatures. The methane conversion and $\mathrm{H}_{2}$ yield are $86.0 \%$ and $68.0 \%$ at $500{ }^{\circ} \mathrm{C}$ and are reached to $99.7 \%$ and $85.6 \%$ at $700{ }^{\circ} \mathrm{C}$. Since methane conversion and $\mathrm{H}_{2}$ yield do not change significantly at $750{ }^{\circ} \mathrm{C}$, the optimum reaction temperature is $700{ }^{\circ} \mathrm{C}$. By increasing the $\mathrm{Ni}$ content, the amount of active sites was increased. But, further amounts of Ni particles started to mobile on the OC surface and they became agglomerated in the calcination step. Therefore, the Ni amount should be justified.

Actually, by increasing the metal loading, active oxygen transfer sites is reduced, which is the result of particle agglomeration. 

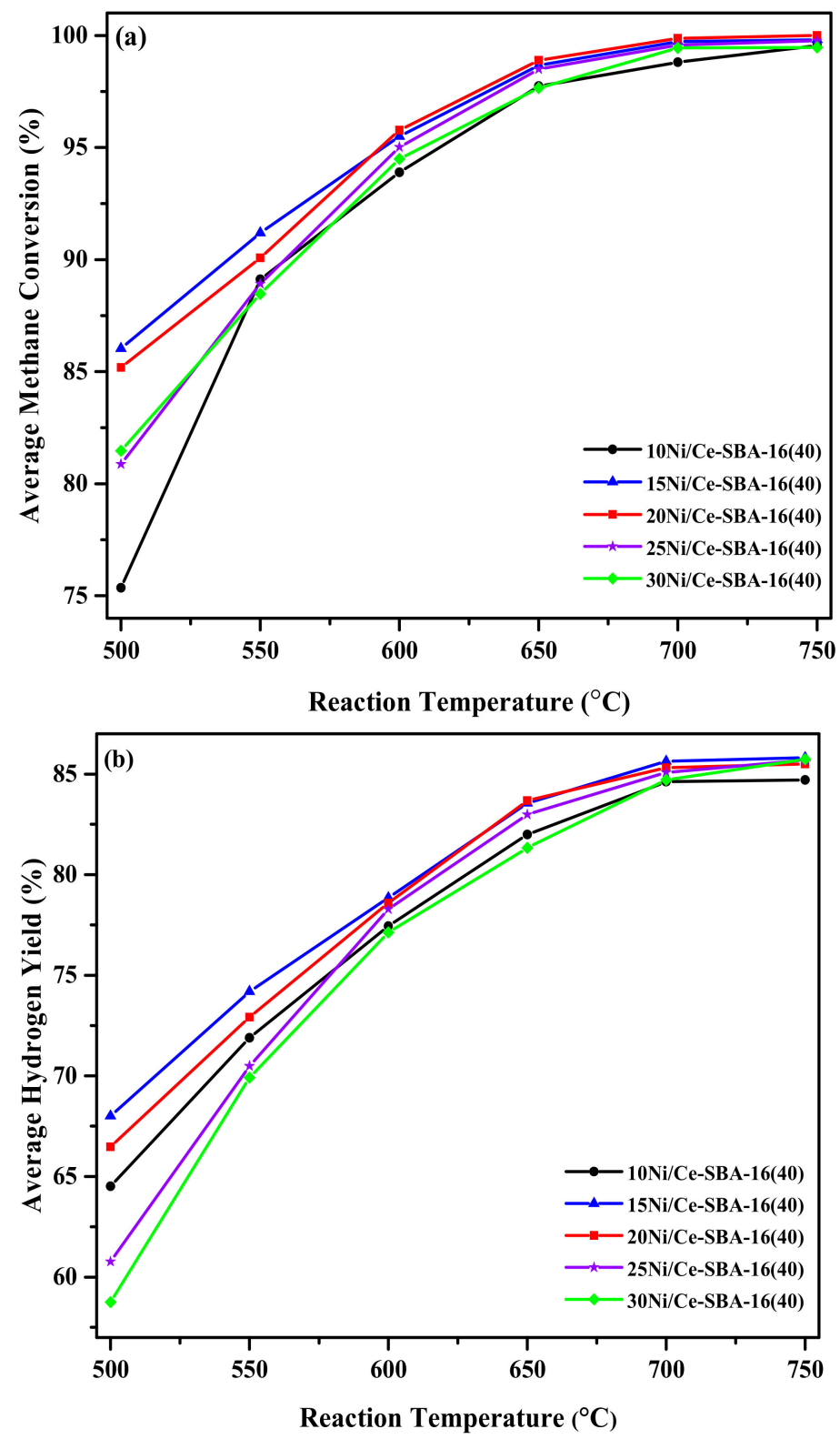

Figure 8. The effect of $\mathrm{Ni}$ weight percent loading on catalytic activity of $\mathrm{xNi} / \mathrm{Ce}-\mathrm{SBA}-16(40) \mathrm{OC}$ at different reaction temperatures: (a) Average methane conversion and (b) Average hydrogen yield.

\subsection{Time-on-Stream Behavior of Oxygen Carrier}

In order to investigate the effect of cerium incorporated into the framework of SBA-16 on the life time of OCs, the prepared samples, including 15Ni/Ce-SBA-16( $\infty)$ and $15 \mathrm{Ni} / \mathrm{Ce}-\mathrm{SBA}-16(40)$, were investigated during 16 cycles under the reaction temperature of $700{ }^{\circ} \mathrm{C}$ and steam to methane ratio of 2. As shown in Figure 9a,b, methane conversion and average hydrogen yield increased through the first seven cycles, but after that, no further increment was observed for 15Ni/Ce-SBA-16(40) OC. The methane conversion increased from 86.6 to $99.5 \%$. The reason is that, during first cycles, not all of the nickel particles burn into oxygen to form nickel oxides and by further reduction process, suitable oxidize phases were formed. But, for $15 \mathrm{Ni} / \mathrm{Ce}-\mathrm{SBA}-16(\infty)$ OC, methane conversion and hydrogen yield first increase to reach $99.9 \%$ and $84.3 \%$, respectively, during four cycles, and then they decrease through three next cycles, but after that, no further reduction was detected, as exhibited in Figure 9a,b, coke formation on the surface of OC causes this reduction of activity [41]. 

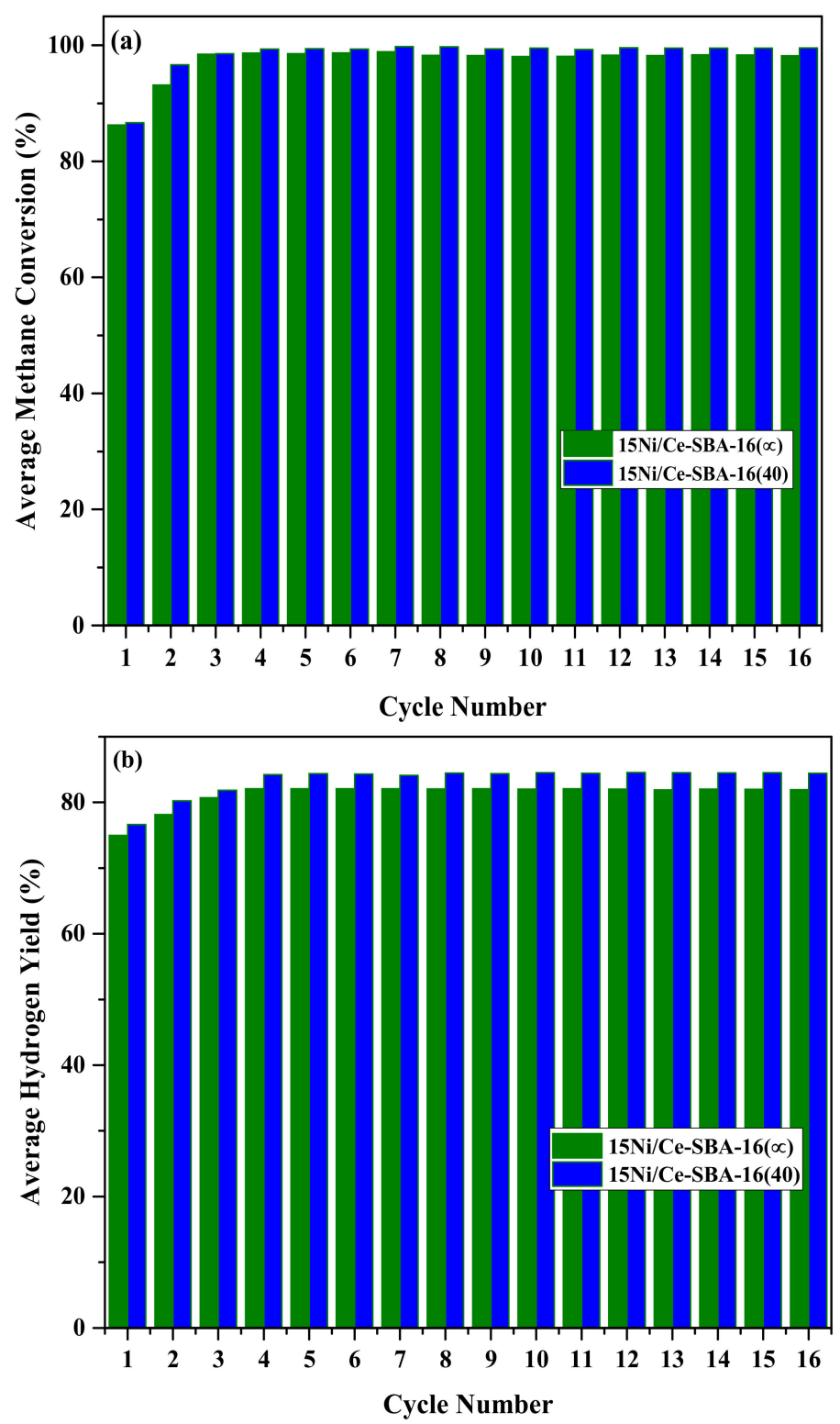

Figure 9. Life time of $15 \mathrm{Ni} / \mathrm{Ce}-\mathrm{SBA}-16(\infty)$ and $15 \mathrm{Ni} / \mathrm{Ce}-\mathrm{SBA}-16(40)$ OCs during 16 redox cycles: (a) Average methane conversion and (b) Average hydrogen yield.

The structural change (BET surface area, pore volume, and pore size) of optimized oxygen carrier after 16 redox cycles is presented in Table 2. The BET surface area of 15Ni/Ce-SBA-16(40) decreased from 207.15 to $112.01\left(\mathrm{~m}^{2} / \mathrm{g}\right)$. Actually, carbon deposited on the Oxygen carrier's surface and reduced specific surface area in reduction step. Furthermore, pore blockage and sintering of OC occurred at $700{ }^{\circ} \mathrm{C}[10]$.

Table 2. Structure characteristics of the deactivated 15Ni/Ce-SBA-16(40) OC after 16 redox cycles.

\begin{tabular}{cccc}
\hline Oxygen Carrier & BET Surface Area $\left(\mathrm{m}^{2} / \mathbf{g}\right)$ & Pore Diameter $(\mathrm{nm})$ & Pore Volume $\left(\mathrm{cm}^{3} / \mathbf{g}\right)$ \\
\hline $15 \mathrm{Ni} / \mathrm{Ce}-\mathrm{SBA}-16(40)$ & 112.01 & 3.98 & 0.12 \\
\hline
\end{tabular}

Figure 10 shows a comparison between wide angle XRD patterns of 15Ni/Ce-SBA-16(40) and $15 \mathrm{Ni} / \mathrm{SBA}-16$ OCs after 16 redox cycles. As can be seen, the intensity of amorphous carbon $\left(2 \theta=44^{\circ}\right)$ in the $15 \mathrm{Ni} / \mathrm{Ce}-\mathrm{SBA}-16(40)$ is less than $15 \mathrm{Ni} / \mathrm{Ce}-\mathrm{SBA}-16(\infty)$, indicating that the less coke deposited on 
the surface area of modified OC. According to 00-021-0771 reference pattern code, $\mathrm{NiCO}_{3}$ is detected at $2 \theta=43.5^{\circ}$ and $52^{\circ} . \mathrm{Ni}_{2} \mathrm{SiO}_{4}$ is presented at $2 \theta=35.5^{\circ}$ and $76.5^{\circ}$ (01-083-2071 reference pattern code).

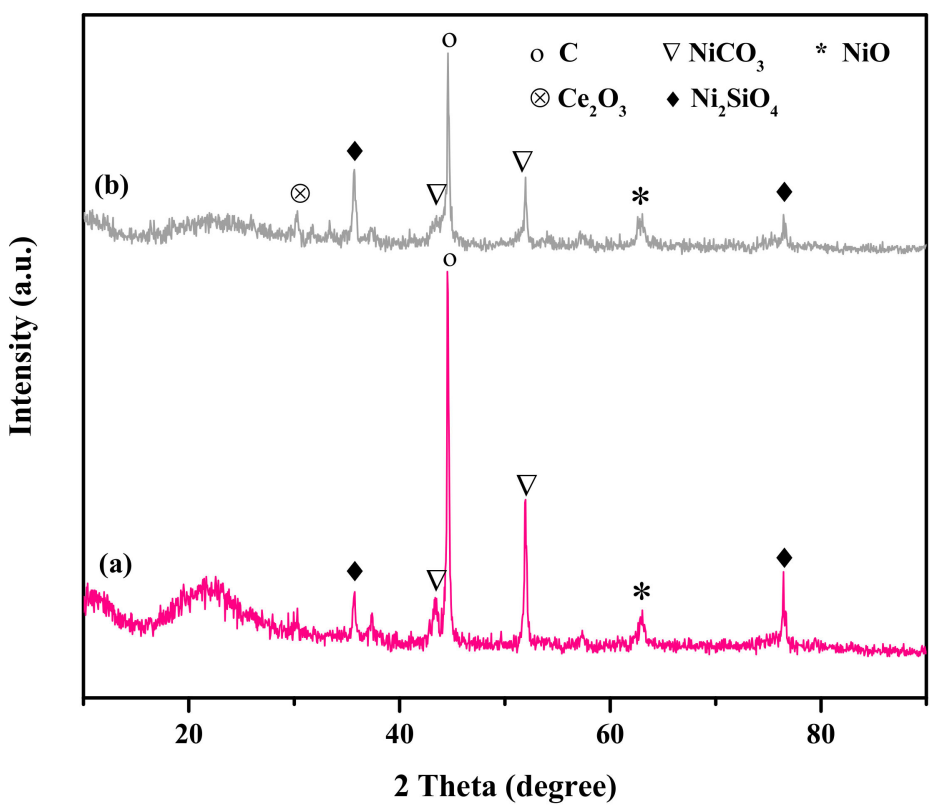

Figure 10. Wide angle XRD patterns of (a) Used 15Ni/Ce-SBA-16( $\infty$ ) and (b) Used 15Ni/Ce-SBA-16(40) OCs.

The energy dispersive X-ray (EDX) carbon result of 15Ni/Ce-SBA-16(40) and 15Ni/Ce-SBA-16( $\infty$ ) OCs after 16 redox cycles at $700{ }^{\circ} \mathrm{C}$ is presented in Table 3 . The results showed that by using cerium modified OC support, deposition of coke was reduced from 3.05 to $0.23 \mathrm{wt} \%$.

Table 3. EDX of used 15Ni/Ce-SBA-16(40) and 15Ni/Ce-SBA-16( $\infty)$ OCs.

\begin{tabular}{cc}
\hline Oxygen Carrier & Carbon (wt \%) \\
\hline $15 \mathrm{Ni} / \mathrm{Ce}-\mathrm{SBA}-16(40)$ & 0.23 \\
$15 \mathrm{Ni} / \mathrm{Ce}-\mathrm{SBA}-16(\infty)$ & 3.06 \\
\hline
\end{tabular}

\section{Experimental Methods}

\subsection{Oxygen Carrier Preparation}

To synthesize the Ni/Ce-SBA-16 OC, the first step was to prepare Ce-SBA-16 support using hydrothermal method. Different ratios of $\mathrm{Si} / \mathrm{Ce}$, including 20,40, 60, and infinite where synthesized to investigate the effect of Ce-promoter in the structure of Ce-SBA-16 support. Then, Ni/Ce-SBA-16 OCs with 10, 15, 20, 25, and $30 \mathrm{wt} \%$ nickel were prepared by wetness impregnation method on the optimum support.

Ce-SBA-16 was prepared using F127, TEOS, n-butanol, and $\mathrm{Ce}\left(\mathrm{NO}_{3}\right)_{3} \cdot 6 \mathrm{H}_{2} \mathrm{O}$ as structure directing agent, silica source, Co-surfactant, and metal precursor. For this purpose, $1.15 \mathrm{~g}$ F127 (Sigma-Aldrich, St. Louis, MO, USA) was dissolved in $\mathrm{HCl}$ (Merck $37 \mathrm{wt} \%$, Darmstadt, Germany) and deionized water under stirring at $40{ }^{\circ} \mathrm{C}$. Then, $3.1 \mathrm{~g}$ n-butanol (Merck) was added to the previous solution with continuous stirring. After complete dissolution, about $7.00 \mathrm{~g}$ TEOS (Merck) and a solution of $\mathrm{Ce}\left(\mathrm{NO}_{3}\right)_{3} \cdot 6 \mathrm{H}_{2} \mathrm{O}$ (Merck) were added dropwise to the slurry to achieve different $\mathrm{Si} / \mathrm{Ce}$ molar ratios and stirred for $120 \mathrm{~min}$. The mixture was then transferred to a Teflon lined autoclave under moderate stirring at $40{ }^{\circ} \mathrm{C}$ for $24 \mathrm{~h}$. Afterwards, it was aged at $100{ }^{\circ} \mathrm{C}$ for $48 \mathrm{~h}$ in an oven. Then, the solid product was filtered, washed several times with double distilled water and ethanol, and dried at $100{ }^{\circ} \mathrm{C}$ for 
one day. The obtained powder was calcined in air at $550{ }^{\circ} \mathrm{C}$ for $6 \mathrm{~h}$ with a heating step of $4{ }^{\circ} \mathrm{C} / \mathrm{min}$. The solid product was designated as Ce-SBA-16(y), where $\mathrm{y}$ is the molar ratio of $\mathrm{Si} / \mathrm{Ce}$.

Nickel was introduced into the Ce-SBA-16(y) support with the incipient wetness impregnation method. The solution of desired amounts of $\mathrm{Ni}\left(\mathrm{NO}_{3}\right)_{2} \cdot 6 \mathrm{H}_{2} \mathrm{O}$ (Merck) in $100 \mathrm{~mL}$ de-ionized water was added to the mixture dropwise at $40{ }^{\circ} \mathrm{C}$. The impregnated solids were dried at $100{ }^{\circ} \mathrm{C}$ overnight and calcined at $700{ }^{\circ} \mathrm{C}$ for $3 \mathrm{~h}$. The synthesized OCs were denoted as $\mathrm{xNi} / \mathrm{Ce}-\mathrm{SBA}-16(\mathrm{y})$, where $\mathrm{x}$ refers to $\mathrm{Ni} w \mathrm{w} \%$.

\subsection{Oxygen Carrier Characterization}

The oxygen carriers and synthesized mesoporous supports were characterized with different methods. The low angle X-ray diffraction (XRD) was carried out with PANalytical (X'pert Pro, Eindhoven, The Netherlands) instrument operating at $40 \mathrm{Kv}$ and $40 \mathrm{~mA}$. The data in the low angle region $\left(2 \theta=0.71-10^{\circ}\right)$ were recorded with a step size of $0.02^{\circ}$. The high angle XRD measurements were implemented by a powder diffractometer (Bruker D8 Advance, Karlsruhe, Germany) via Cu K $\alpha$ radiation at $40 \mathrm{Kv}$ and $40 \mathrm{~mA}$. In high angle $\mathrm{XRD}$, samples were run under a step scan mode in the angular $2 \theta$ range of $10-90^{\circ}$, with a step size rating of $0.05^{\circ} / \mathrm{s}$. Transmission electron micrograph (TEM) images of samples were collected with a Zeiss-EM10C transmission electron microscope (Oberkochen, Germany), employing an accelerating voltage of $100 \mathrm{kV}$. The surface morphology of samples was studied by scanning electron microscopy (SEM). The SEM images were collected using a TESCAN vega3 equipped with an energy dispersive $X$-ray (EDX) spectroscopy. For measuring the specific surface area of OCs, Brunauer-Emmett-Teller (BET) method was used by nitrogen adsorption/desorption isotherms. About $0.08 \mathrm{~g}$ of the samples were degassed at $250{ }^{\circ} \mathrm{C}$ with nitrogen in an automated gas adsorption instrument (ASAP-2020, Micromeritics, Atlanta, GA, USA). The pore size distribution and cumulative pore volume were achieved by $\mathrm{BJH}$ method and desorption branches of adsorption isotherms, respectively.

\subsection{Process Activity}

The performance of synthesized oxygen carriers in CL-SMR process was evaluated at atmospheric pressure in a fixed bed reactor due to the operational limits. It is noteworthy to say that previous works also used a fixed bed reactor for chemical looping reforming process [15,43,44]. In this regard, the oxygen carriers were tested by reduction-oxidation (redox) multi-cycles of gas-solid reaction. The stainless steel reactor (diameter: $16 \mathrm{~mm}$, height: $1000 \mathrm{~mm}$ ) was inserted into a vertical furnace, as shown schematically in Figure 11. Typically, $1 \mathrm{~g}$ of freshly oxygen carrier was introduced into the reactor on a thin porous layer in the middle of it. The volumetric flow rate of the gaseous feed stream consisting $\mathrm{CH}_{4}(99.99 \%)$, $\mathrm{Ar}(99.99 \%)$ was controlled using distinct MFCs to 48.1 and $87.4 \mathrm{~mL} / \mathrm{min}$. The steam was injected with an HPLC pump to an evaporator and then mixed with gaseous mixture prior to the reactor. The reduction section was performed at temperatures in the range of $500-750{ }^{\circ} \mathrm{C}$, with an increment of $50{ }^{\circ} \mathrm{C}$ for $50 \mathrm{~min}$. Oxidation section was performed before each reduction period for $30 \mathrm{~min}$ with the purpose of reoxidizing the oxygen carriers and burning the deposited carbon. In this section, $\mathrm{O}_{2}(20 \mathrm{vol} \%)$ diluted with Ar was fed to the reactor with the flow rate of $44.0 \mathrm{~mL} / \mathrm{min}$. The oxidation and reduction periods were separated by 3 min purging of argon.

The effluent of the reactor was passed through a condenser and separator to liquefy the steam and to remove any solid particles. Then, the product and unreacted gases were analyzed by an online Bruker 450 gas chromatograph equipped with a thermal conductivity detector (TCD).

Methane conversion $\left(\mathrm{X}_{\mathrm{CH}_{4}}\right)$ and hydrogen production yield $\left(\mathrm{y}_{\mathrm{H}_{2}}\right)$ were calculated as follows:

$$
\mathrm{X}_{\mathrm{CH}_{4}}=\frac{\left(F_{\mathrm{CH}_{4}}\right)_{\text {in }}-\left(F_{\mathrm{CH}_{4}}\right)_{\text {out }}}{\left(F_{\mathrm{CH}_{4}}\right)_{\text {in }}} \times 100
$$




$$
\mathrm{y}_{\mathrm{H}_{2}}=\frac{F_{\mathrm{H}_{2}}}{2 \times F_{\mathrm{CH}_{4}}} \times 100
$$

where $F_{\mathrm{H}_{2}}, F_{\mathrm{CH}_{4}}$ represent the outlet molar flow rate of hydrogen and the inlet molar flow rate of methane, respectively.

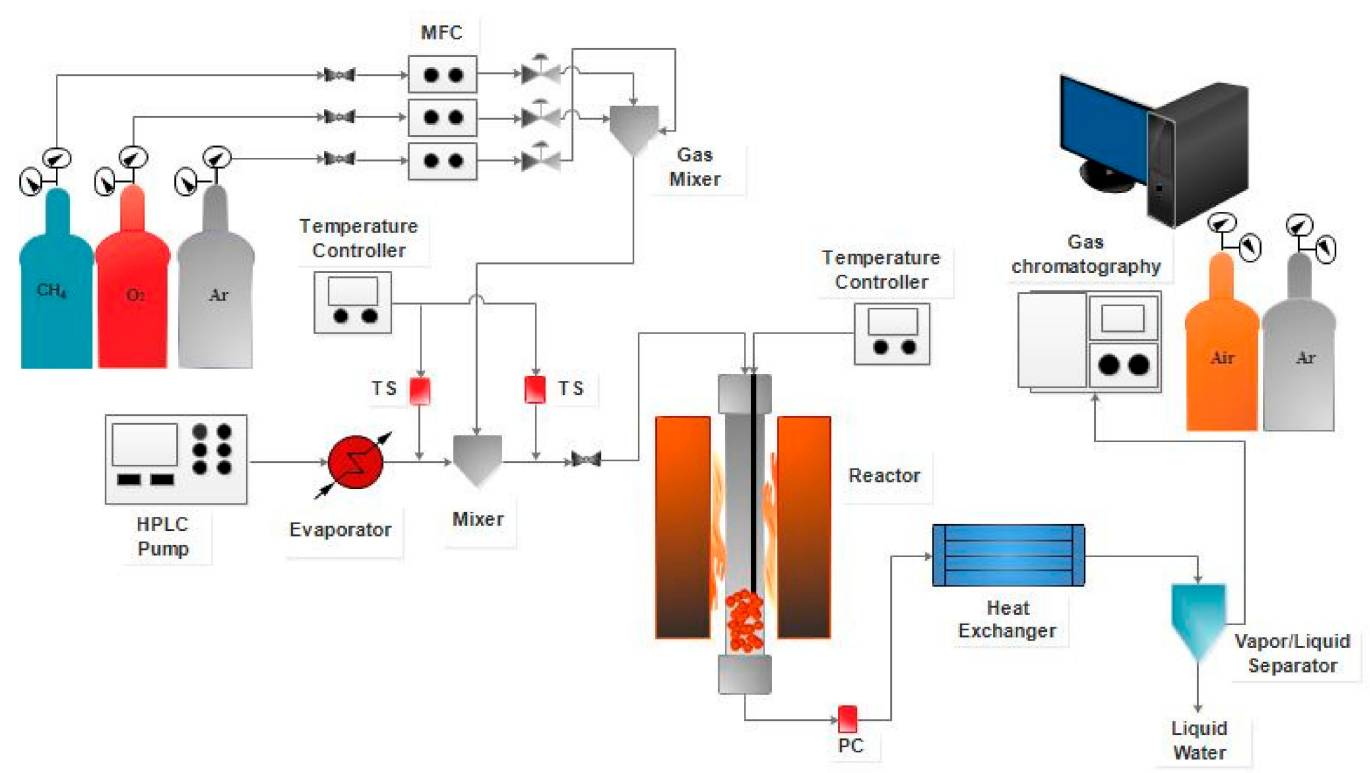

Figure 11. Reactor system for CL-SMR.

\section{Conclusions}

A series of mesoporous cerium containing SBA-16 (Ce-SBA-16) were synthesized via direct hydrothermal method as the supporting material for Ni-based oxygen carrier in a CL-SMR process. The effect of Ni loading (10-30 wt \%), various Si/Ce molar ratios (20-60) in the support, reaction temperature $\left(500-750{ }^{\circ} \mathrm{C}\right)$, and life time of oxygen carrier over 16 redox cycles were successfully investigated. The characterization results showed that cerium was well incorporated into the silica framework of SBA-16 without provoking structure. The results of wide angle XRD and SEM revealed that the incorporation of $\mathrm{CeO}_{2}$ in the channels of SBA-16 caused the formation of nickel metallic particles with smaller size. This leads to a better dispersion of $\mathrm{NiO}$ particles on the surface of supports. In addition, it prevents the formation of coke during the process that is in agreement with EDX and XRD results of used oxygen carriers. The xNi/Ce-SBA-16(y) with $\mathrm{x}$ and $\mathrm{y}$ value of 15 and 40, respectively, revealed the highest catalytic activity and long-term stability in the CL-SMR process. The reduction temperature showed a significant consequence on methane conversion in all of the prepared samples. The methane conversion over $15 \mathrm{Ni} / \mathrm{Ce}-\mathrm{SBA}-16(40)$ oxygen carrier increased from 86.0 to $99.7 \%$, with temperature rising from $500-700{ }^{\circ} \mathrm{C}$. The stability tests of $15 \mathrm{Ni} / \mathrm{Ce}-\mathrm{SBA}-16(\infty)$ and $15 \mathrm{Ni} / \mathrm{Ce}-\mathrm{SBA}-16(40)$ showed that the incorporation of cerium could significantly improve the lifetime of oxygen carrier at high reduction temperatures.

Author Contributions: Maryam Meshksar, Sanaz Daneshmand-Jahromi and Ali Hafizi conceived and designed the experiments; Maryam Meshksar and Sanaz Daneshmand-Jahromi performed the experiments; Maryam Meshksar and Sanaz Daneshmand-Jahromi performed catalyst synthesis; Maryam Meshksar, Sanaz Daneshmand-Jahromi and Ali Hafizi analyzed the data; Mohammad Reza Rahimpour contributed reagents/materials/analysis tools; Mohammad Reza Rahimpour participated in the analysis and interpretation of characterization results; and Maryam Meshksar and Sanaz Daneshmand-Jahromi wrote the paper.

Conflicts of Interest: The authors declare no conflict of interest. 


\section{References}

1. Udomsirichakorn, J.; Salam, P.A. Review of hydrogen-enriched gas production from steam gasification of biomass: The prospect of CaO-based chemical looping gasification. Renew. Sustain. Energy Rev. 2014, 30, 565-579. [CrossRef]

2. Neal, L.; Shafiefarhood, A.; Li, F. Effect of core and shell compositions on $\mathrm{MeO}_{x} @ \mathrm{La}_{y} \mathrm{Sr}_{1-y} \mathrm{FeO}_{3}$ core-shell redox catalysts for chemical looping reforming of methane. Appl. Energy 2015, 157, 391-398. [CrossRef]

3. Wang, Y.; Chen, M.; Liang, T.; Yang, Z.; Yang, J.; Liu, S. Hydrogen generation from catalytic steam reforming of acetic acid by Ni/attapulgite catalysts. Catalysts 2016, 6, 172. [CrossRef]

4. Neal, L.; Shafiefarhood, A.; Li, F. Significantly improved catalytic performance of Ni-based MgO catalyst in steam reforming of phenol by inducing mesostructure. Catalysis 2015, 5, 1721-1736. [CrossRef]

5. Ryden, M.; Ramos, $\mathrm{P}$. $\mathrm{H}_{2}$ production with $\mathrm{CO}_{2}$ capture by sorption enhanced chemical-looping reforming using $\mathrm{NiO}$ as oxygen carrier and $\mathrm{CaO}$ as $\mathrm{CO}_{2}$ sorbent. Fuel Process. Technol. 2012, 96, 27-36. [CrossRef]

6. Irani, M.; Alizadehdakhel, A.; Pour, A.N.; Hoseini, N.; Adinehnia, M. CFD modeling of hydrogen production using steam reforming of methane in monolith reactors: Surface or volume-base reaction model? Int. J. Hydrogen Energy 2011, 36, 15602-15610. [CrossRef]

7. Bernareggi, M.; Dozzi, M.V.; Bettini, L.G.; Ferretti, A.M.; Chiarello, G.L.; Selli, E. Flame-Made Cu/TiO 2 and $\mathrm{Cu}-\mathrm{Pt} / \mathrm{TiO}_{2}$ Photocatalysts for Hydrogen Production. Catalysts 2017, 7, 301. [CrossRef]

8. Zhu, X.; Li, K.; Wei, Y.; Wang, H.; Sun, L. Chemical-looping steam methane reforming over a $\mathrm{CeO}_{2}-\mathrm{Fe}_{2} \mathrm{O}_{3}$ oxygen carrier: Evolution of its structure and reducibility. Energy Fuels 2014, 28, 754-760. [CrossRef]

9. Zhang, X.; Jin, H. Thermodynamic analysis of chemical-looping hydrogen generation. Appl. Energy 2013, 112, 800-807. [CrossRef]

10. Hafizi, A.; Rahimpour, M.R.; Hassanajili, S. Calcium promoted $\mathrm{Fe} / \mathrm{Al}_{2} \mathrm{O}_{3}$ oxygen carrier for hydrogen production via cyclic chemical looping steam methane reforming process. Int. J. Hydrogen Energy 2015, 40, 16159-16168. [CrossRef]

11. Hafizi, A.; Rahimpour, M.R.; Hassanajili, S. Hydrogen production by chemical looping steam reforming of methane over Mg promoted iron oxygen carrier: Optimization using design of experiments. J. Taiwan Inst. Chem. Eng. 2016, 62, 140-149. [CrossRef]

12. Zhao, Z.; Ren, P.; Li, W. Supported Ni catalyst on a natural halloysite derived silica-alumina composite oxide with unexpected coke-resistant stability for steam- $\mathrm{CO}_{2}$ dual reforming of methane. RSC Adv. 2016, 6, 49487-49496. [CrossRef]

13. Mishra, A.; Galinsky, N.; He, F.; Santiso, E.E.; Li, F. Perovskite-structured $\mathrm{AMn}_{x} \mathrm{~B}_{1-x} \mathrm{O}_{3}(\mathrm{~A}=\mathrm{Ca}$ or $\mathrm{Ba}$; $\mathrm{B}=\mathrm{Fe}$ or $\mathrm{Ni}$ ) redox catalysts for partial oxidation of methane. Catal. Sci. Technol. 2016. [CrossRef]

14. Jiang, B.; Dou, B.; Song, Y.; Zhang, C.; Du, B.; Chen, H.; Wang, C.; Xu, Y. Hydrogen production from chemical looping steam reforming of glycerol by Ni-based oxygen carrier in a fixed-bed reactor. Chem. Eng. J. 2015, 280, 459-467. [CrossRef]

15. Hafizi, A.; Rahimpour, M.R.; Hassanajili, S. Hydrogen production via chemical looping steam methane reforming process: Effect of cerium and calcium promoters on the performance of $\mathrm{Fe}_{2} \mathrm{O}_{3} / \mathrm{Al}_{2} \mathrm{O}_{3}$ oxygen carrier. Appl. Energy 2015, 165, 685-694. [CrossRef]

16. Forutan, H.R.; Karimi, E.; Hafizi, A.; Rahimpour, M.R.; Keshavarz, P. Expert representation chemical looping reforming: A comparative study of $\mathrm{Fe}, \mathrm{Mn}, \mathrm{Co}$ and $\mathrm{Cu}$ as oxygen carriers supported on $\mathrm{Al}_{2} \mathrm{O}_{3}$. J. Ind. Eng. Chem. 2015, 21, 900-911. [CrossRef]

17. Tang, M.; Xu, L.; Fan, M. Progress in oxygen carrier development of methane-based chemical-looping reforming: A review. Appl. Energy 2015, 151, 143-156. [CrossRef]

18. Saeidia, S.; Fazlollahi, F.; Najarid, S.; Iranshahi, D.; Klemeše, J.J.; Baxter, L.L. Hydrogen production: Perspectives, separation with special emphasis on kinetics of WGS reaction: A state-of-the-art review. J. Ind. Eng. Chem. 2017, 49, 1-25. [CrossRef]

19. Ortiz, M.; de Diego, L.F.; Abad, A.; García-Labiano, F.; Gayán, P.; Adánez, J. Catalytic Activity of Ni-Based Oxygen-Carriers for Steam Methane Reforming in Chemical-Looping Processes. Energy Fuels 2012, 26, 791-800. [CrossRef]

20. Daneshmand-Jahromi, S.; Rahimpour, M.R.; Meshksar, M.; Hafizi, A. Hydrogen production from cyclic chemical looping steam methane reforming over yttrium promoted Ni/SBA-16 oxygen carrier. Catalysts 2017, 7, 286. [CrossRef] 
21. Zafar, Q.; Mattisson, T.; Gevert, B. Redox investigation of some oxides of transition-state metals $\mathrm{Ni}, \mathrm{Cu}, \mathrm{Fe}$, and $\mathrm{Mn}$ supported on $\mathrm{SiO}_{2}$ and $\mathrm{MgAl}_{2} \mathrm{O}_{4}$. Energy Fuels 2006, 20, 34-44. [CrossRef]

22. De Diego, L.F.; Ortiz, M.; Garcia-Labiano, F.; Adanez, J.; Abad, A.; Gayan, P. Synthesis gas generation by chemical-looping reforming using a Nibased oxygen carrier. Energy Procedia 2009, 1, 3-10. [CrossRef]

23. Liu, D.; Quek, X.-Y.; Wah, H.H.A.; Zeng, G.; Li, Y.; Yang, Y. Carbon dioxide reforming of methane over nickel-grafted SBA-15 and MCM-41 catalysts. Catal. Today 2009, 148, 243-250. [CrossRef]

24. Luo, J.; Yu, Z.; Ng, C.; Au, C. $\mathrm{CO}_{2} / \mathrm{CH}_{4}$ reforming over $\mathrm{Ni}-\mathrm{La}_{2} \mathrm{O}_{3} / 5 \mathrm{~A}$ : An investigation on carbon deposition and reaction steps. J. Catal. 2000, 194, 198-210. [CrossRef]

25. Qin, L.; Sakamoto, Y.; Anderson, M.W. Controlling the window size in mesoporous SBA-16. Phys. Chem. Chem. Phys. 2014, 16, 15640-15645. [CrossRef] [PubMed]

26. Lindo, M.; Vizcaíno, A.; Calles, J.; Carrero, A. Ethanol steam reforming on Ni/Al-SBA-15 catalysts: Effect of the aluminium content. Int. J. Hydrogen Energy 2011, 35, 5895-5901. [CrossRef]

27. Qian, L.; Ma, Z.; Ren, Y.; Shi, H.; Yue, B.; Feng, S.; Shen, J.; Xie, S. Investigation of La promotion mechanism on Ni/SBA-15 catalysts in $\mathrm{CH}_{4}$ reforming with $\mathrm{CO}_{2}$. Fuel 2014, 122, 47-53. [CrossRef]

28. Wang, N.; Chu, W.; Zhang, T.; Zhao, X.S. Synthesis, characterization and catalytic performances of Ce-SBA-15 supported nickel catalysts for methane dry reforming to hydrogen and syngas. Int. J. Hydrogen Energy 2012, 37, 19-30. [CrossRef]

29. Hafizi, A.; Rahimpour, M.R.; Hassanajili, S. High purity hydrogen production via sorption enhanced chemical looping reforming: Application of $22 \mathrm{Fe}_{2} \mathrm{O}_{3} / \mathrm{MgAl}_{2} \mathrm{O}_{4}$ and $22 \mathrm{Fe}_{2} \mathrm{O}_{3} / \mathrm{Al}_{2} \mathrm{O}_{3}$ as oxygen carriers and cerium promoted $\mathrm{CaO}$ as $\mathrm{CO}_{2}$ sorbent. Appl. Energy 2016, 169, 629-641. [CrossRef]

30. Wang, K.; Dou, B.; Jiang, B.; Song, Y.; Zhang, C.; Zhang, Q.; Chen, H.; Xu, Y. Renewable hydrogen production from chemical looping steam reforming of ethanol using $x \mathrm{CeNi} / \mathrm{SBA}-15$ oxygen carriers in a fixed-bed reactor. Int. J. Hydrogen Energy 2016, 41, 12899-12909. [CrossRef]

31. Zhang, S.; Muratsugu, S.; Ishiguro, N.; Tada, M. Ceria-Doped Ni/SBA-16 Catalysts for Dry Reforming of Methane. ACS Catal. 2013, 3, 1855-1864. [CrossRef]

32. Li, D.; Zeng, L.; Li, X.; Wang, X.; Ma, H.; Assabumrungrat, S.; Gong, J. Ceria-promoted Ni/SBA-15 catalysts for ethanol steam reforming with enhanced activity and resistance to deactivation. Appl. Catal. B Environ. 2015, 176, 532-541. [CrossRef]

33. Kong, L.; Li, J.; Zhao, Z.; Liu, Q.; Sun, Q.; Liu, J.; Wei, Y. Oxidative dehydrogenation of ethane to ethylene over Mo-incorporated mesoporous SBA-16 catalysts: The effect of $\mathrm{MoO}_{\mathrm{x}}$ dispersion. Appl. Catal. A Gen. 2016, 510, 84-97. [CrossRef]

34. Ramanathan, A.; Zhu, H.; Maheswari, R.; Thapa, P.S.; Subramaniam, B. Comparative study of $\mathrm{Nb}$-incorporated cubic mesoporous silicates as epoxidation catalysts. Ind. Eng. Chem. Res. 2015, 54, 4236-4242. [CrossRef]

35. Wu, F.; Zhao, Y.M.; Liang, P. An Investigation on Properties of Sn-SBA-16 Synthesized without Mineral Acid Added. Adv. Mater. Res. Trans. Tech. Publ. 2013, 707-710. [CrossRef]

36. Tan, Y.; Li, Y.; Wei, Y.; Wu, Z.; Yan, J.; Pan, L.; Liu, Y. The hydroxyalkylation of phenol with formaldehyde over mesoporous $\mathrm{M}(\mathrm{Al}, \mathrm{Zr}, \mathrm{Al}-\mathrm{Zr})-\mathrm{SBA}-15$ catalysts: The effect on the isomer distribution of bisphenol $\mathrm{F}$. Catal. Commun. 2015, 67, 21-25. [CrossRef]

37. Huirache-Acuña, R.; Pawelec, B.; Loricera, C.; Rivera-Muñoz, E.; Nava, R.; Torres, B.; Fierro, J. Comparison of the morphology and HDS activity of ternary Ni (Co)-Mo-W catalysts supported on Al-HMS and Al-SBA-16 substrates. Appl. Catal. B Environ. 2012, 125, 473-485. [CrossRef]

38. Dong, Y.; Zhan, X.; Niu, X.; Li, J.; Yuan, F.; Zhu, Y.; Fu, H. Facile synthesis of Co-SBA-16 mesoporous molecular sieves with EISA method and their applications for hydroxylation of benzene. Microporous Mesoporous Mater. 2014, 185, 97-106. [CrossRef]

39. Rodríguez-Castellón, E.; Díaz, L.; Braos-García, P.; Mérida-Robles, J.; Maireles-Torres, P.; Jiménez-López, A.; Vaccari, A. Nickel-impregnated zirconium-doped mesoporous molecular sieves as catalysts for the hydrogenation and ring-opening of tetralin. Appl. Catal. A Gen. 2003, 240, 83-94. [CrossRef]

40. Akbari-Emadabadi, S.; Rahimpour, M.R.; Hafizi, A.; Keshavarz, P. Production of hydrogen-rich syngas using Zr modified Ca-Co bifunctional catalyst-sorbent in chemical looping steam methane reforming. Appl. Energy 2017, 206, 51-62. [CrossRef] 
41. Meshksar, M.; Daneshmand-Jahromi, S.; Rahimpour, M.R. Synthesis and characterization of cerium promoted $\mathrm{Ni} / \mathrm{SBA}-16$ oxygen carrier in cyclic chemical looping steam methane reforming. J. Taiwan Inst. Chem. Eng. 2017, 76, 73-82. [CrossRef]

42. Akbari-Emadabadi, S.; Rahimpour, M.R.; Hafizi, A.; Keshavarz, P. Promotion of Ca-Co bifunctional catalyst/sorbent with yttrium hydrogen production in modified chemical looping steam methane reforming process. Catalysts 2017, 7, 270. [CrossRef]

43. Zhu, X.; Wei, Y.; Wang, H.; Li, K. Ce-Fe oxygen carriers for chemical-looping steam methane reforming. Int. J. Hydrogen Energy 2013, 38, 4492-4501. [CrossRef]

44. Zheng, Y.E.; Zhu, X.; Wang, H.; Li, K.Z.; Wang, Y.H.; Wei, Y.G. Characteristic of macroporous $\mathrm{CeO}_{2}-\mathrm{ZrO}_{2}$ oxygen carrier for chemical-looping steam methane reforming. J. Rare Earths 2014, 32, 842-848. [CrossRef]

2018 by the authors. Licensee MDPI, Basel, Switzerland. This article is an open access article distributed under the terms and conditions of the Creative Commons Attribution (CC BY) license (http://creativecommons.org/licenses/by/4.0/). 